\title{
Linking climate variables to large-scale spatial pattern and risk of citrus Huanglongbing: a hierarchical Bayesian modeling approach
}

Huanglongbing (HLB) is one of the most important diseases for the citriculture in the world. Knowledge of climatic factors linked to HLB risk at the large spatial scale is limited. We gathered HLB presence/absence data from official surveys conducted in the state of Minas Gerais, Brazil, for 13 years. The total count of orange and mandarin orchards, and mean orchard area, normalized to a spatial grid of 60 cells $(55 \times 55 \mathrm{~km})$, were derived from the same database. The monthly climate normal (1984 to 2013) on rainfall, mean temperature, and wind speed were split into rainy (September to April) and dry (May to August) seasons (annual summary was retained) were also obtained for each grid cell. Two hierarchical Bayesian modeling approaches were evaluated both based on the integrated nested Laplace approximation methodology. The first, the climate covariates model (CC model), used orchard, climate, and the spatial effect as covariates. The second, principal components (PC model), used the first three components from a PCA of all variables and the spatial effect as covariates. Both models showed an inverse relationship between posterior prevalence and mean temperature during dry season across the grid cells. Annual wind speed, as well as annual and rainy season rainfall, contributed significantly towards HLB risk, in the CC and PC models, respectively. A partial influence of neighboring regions on HLB risk was observed. These results should assist policymakers in defining regions at HLB risk and monitoring strategies to avoid further spread in the target region.

Citrus greening | epidemiology | disease risk | mapping | sweet orange | epidemic

\section{Introduction}

Huanglongbing (HLB), also referred to as citrus greening, is among the most destructive citrus diseases worldwide, including in Brazil (Gottwald et al. 2010; Bassanezi et al. 2020). HLB was first reported in São Paulo (SP) state of Brazil during the 2004 season (Coletta-Filho et al. 2004; do Carmo Teixeira et al. 2005). Advancing thirteen years, the incidence of HLB in sweet orange orchards in the citrus belt (i.e., SP and Minas Gerais; MG) has increased to $\sim 19 \%$, potentially estimated to 37 million trees (Fundecitrus 2019). In 2018, over $57 \%$ of orchards, including mandarins and sweet oranges in MG were affected by the HLB (Alves et al. 2020). A 10-year analysis indicated the spread of the HLB epidemic in MG was estimated at $25.7 \mathrm{~km}$ per year and $45.9 \mathrm{~km}$ per year in central and south of MG and the border of São Paulo, respectively (Alves et al. 2020).
Three Gram-negative bacterium species of the genus Candidatus Liberibacter are responsible for causing HLB; namely, $\mathrm{Ca}$. L. africanus (Jagoueix et al. 1994), Ca. L. americanus (Coletta-Filho et al. 2004; do Carmo Teixeira et al. 2005) and Ca. L. asiaticus (Jagoueix et al. 1994). The predominant species in Brazil was Ca. L. americanus, until 2008 when a shift in the population dynamics occurred and $\mathrm{Ca}$. L. asiaticus (CLas) became the most prevalent species $(>99.9 \%)$ found in orchards (Lopes et al. 2009; Bassanezi et al. 2020). These bacteria possess a persistent propagative relationship with phloemprobing psyllid vectors, nymphs, and adults, which are mainly responsible for their spread and transmission under natural conditions (Ammar et al. 2016).

The Asian citrus psyllid, Diaphorina citri, is the primary vector responsible for the spread and transmission of $\mathrm{Ca}$. L. americanus and $\mathrm{Ca}$. L. asiaticus (do Carmo Teixeira et al., 2005; Bové, 2006). 
Cognisance must be taken of respective psyllid lifecycles, i.e., egg, nymph, and adult, with pathogen acquisition, replication, transmission, survival, and spread, affecting the onset and spread (Razi et al. 2014; Teck et al. 2011). Developing epidemic intervention strategies, and the successful implementation thereof is reliant on determining factors driving disease development and spread (Madden et al. 2007).

The extent of HLB throughout Brazilian states can be attributed to the psyllid vectors' capability of short (plant-to-plant and within orchard; 5-320 m) and long-distance (between orchard; $\sim 2.5 \mathrm{~km}$ ) movement via passive and active strategies, i.e., windassisted dispersal and consecutive short flights, respectively (Carmo-Sousa et al. 2020; Antolinez et al. 2021). Additionally, the use of infected propagative material through grafting has also been demonstrated to transmit HLB and can thus contribute to the dissemination of the pathogen (van Vuuren \& da Graça, 1993). Orchard-level studies indicate HLBinfected tree clustering occurs as a result of vector movement, resulting in an edge effect to either nearby trees enlarging established foci or generating new foci (Bassanezi et al. 2005). At a regional level, in Minas Gerais state, an aggregated spatial pattern was associated with HLB orchards, albeit a stronger aggregation in mandarin (Citrus reticulata Blanco) than in sweet orange (C. sinensis Osbeck) orchards (Alves et al. 2020).

Due to HLB's polyetic nature, quantitative epidemiological studies pose challenges, i.e., multiseason data are required and eradication of the symptomatic plants reduces the opportunity to continuously monitor disease progress (Gottwald 2010). Where multi-year field studies could be conducted, numerous environmental factors are associated with the spatial and temporal progress of HLB. Rainfall was positively correlated with relative HLB incidence in Florida, further suggesting that higher rainfall is associated with a greater risk for HLB occurrence, maybe due to plant physiological response or its effect on vector population dynamics (Shimwela et al. 2018). When considering temperature parameters, the psyllid vector has a narrower tolerance temperature threshold than that of its disease-causing bacterium (Gutierrez and Ponti 2013). Furthermore, within the species complex, $\mathrm{Ca}$. L. asiaticus tolerates higher temperatures than that of $\mathrm{Ca}$. L. americanus, assumed to be part of the reason for the shift (Lopes et al. 2009; Gasparoto et al. 2012). Considerations of optimal host environments also need to be accounted for as flushing, newly emerging leaves, has been associated with higher densities of the psyllid vector (Gutierrez and Ponti 2013; LewisRosenblum et al. 2015).
Preventative measures in place to mitigate HLB include exclusion and eradication strategies, i.e., quarantine, planting certified-healthy nursery trees preventing pathogen introduction, and insecticide applications to suppress vector populations and dissemination (Bové 2006; Bassanezi et al. 2020). Additionally, the reactive eradication of symptomatic trees to reduce inoculum reservoirs in order to mitigate losses and the spread of HLB, which comes at a high cost to growers (Lopes et al. 2008). In response to the HLB epidemic in Brazil, statewide initiatives monitor the occurrence of HLB and enforce orchard clearing at a $28 \%$ incidence threshold (Craig et al., 2018; Bassanezi et al., 2020). Ultimately, an areawide approach that includes all orchard sizes and citrus types is the most appropriate for the effective management of HLB (Bassanezi et al. 2013).

The state of Minas Gerais ranks third in the production of citrus in Brazil (IBGE, 2018 cited in Carvalho et al., 2019) and is considered one of the four major citrus production poles of the country (Passos et al., 2018). In this study, we aimed to link climate variables to the current spatial distribution of the prevalence of HLB in Minas Gerais, through the application of hierarchical Bayesian spatial modeling. Consequently, such modeling approaches enable us to quantify and visualize the disease spatial distribution including the effect of a range of covariates and random spatial effects. The methodology is similar to a recent study that modeled the effect of climatic variables on the spatial distribution of Xylella fastidiosa in regions of Spain and Italy (Cendoya et al. 2020). We hypothesize that climatic variables (temperature, precipitation, and wind speed) and orchard-related variables, such as orchard size and citrus species affect the geographical distribution of HLB prevalence in Minas Gerais, Brazil. Potentially, these results could assist authorities, plant health officers, and producers in the continuation of disease monitoring and if needed the adjustment of management strategies targeted to the probability of HLB prevalence.

\section{Material and methods}

\section{Data sources and predictor variables}

HLB occurrence data. HLB occurrence (presence and absence) data were gathered by the Instituto Mineiro de Agropecuaria (IMA). The state agency has been monitoring HLB in citrus orchards in Minas Gerais state since its first detection in 2005. IMA surveys all citrus orchards, however, mandarin and sweet orange are the focus of this study, across municipalities and categorizes risk for HLB. A risk 1 category is associated with municipalities where HLB 
has already been detected in any citrus orchard. Whereas neighboring municipalities, where HLB has not yet been detected, are placed into a risk 2 category. All citrus orchards located in the municipalities under risks 1 and 2 are monitored, if risk categories are not attributed to municipalities the orchards within those municipalities are not monitored. All plants in the orchards are inspected for HLB and HLB-like symptoms by trained inspectors. Once an HLB-symptomatic plant is detected, samples are sent to a laboratory for confirmation by polymerase chain reaction (PCR) assays.

All positive and negative (HLB-present or absent) orchards are included in the database with their respective location (latitude and longitude) and other attributes related to the orchard. A full description of the data is available elsewhere (Alves et al. 2020) and is available in a citable research compendium (osf.io/23ghm). In this study, we used a more complete dataset that included the recent addition of data to the database, which was the second semester of 2018. Data were aggregated into $0.5 \times 0.5$ decimal degrees spatial grid (lower distance for all grid cells to have at least one neighbor cell), which is equivalent to $55.5 \times 55.5 \mathrm{~km}$ grid at the Equator (Figure 1).

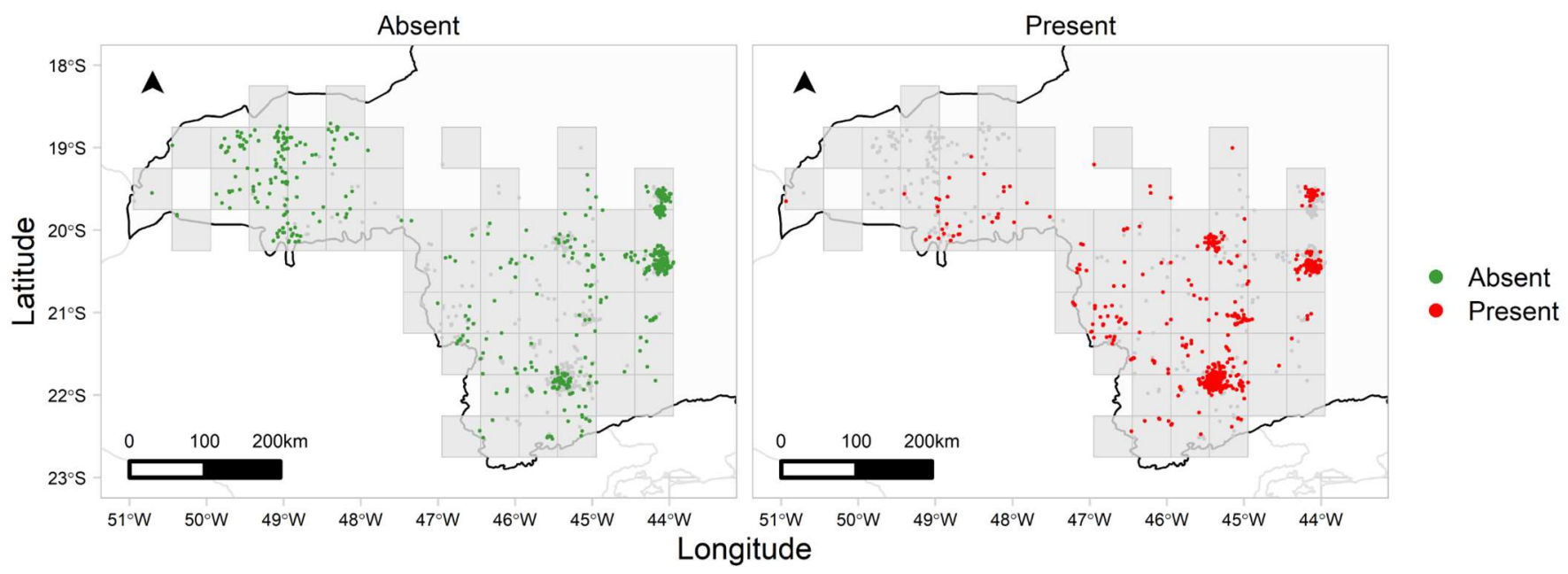

Figure 1: Spatial distribution of citrus orchards with and without HLB presence up to 2018 in Minas Gerais, Brazil. Gray squares represent the grid cells in which data were aggregated.

Previous works have suggested the effect of the area of an orchard on the temporal and spatial progression of the disease due to the edge effect in which the disease tend to expand from the orchard edge (Gottwald et al. 2010; Leal et al. 2010; Shen et al. 2013; Gasparoto et al. 2018; Alves et al. 2020). Consequently, the mean orchard areas were calculated by grid cells. The log-transformed area was utilized as a candidate for spatial modeling. Moreover, the frequencies of mandarins and orange orchards in each grid cell were computed, as recently demonstrated the south region of $M G$ has a high concentration of mandarins, contrasting to the western MG, which has more sweet orange orchards (Alves et al. 2020). Because of the presence of high values in certain grid cells all values were logtransformed. In order to avoid issues with the logtransformed data where zero counts were present in orchard frequency, as $\log (0)$ is undefined, 1 was added to all values of orchard frequency.

Climate data. Climatic data were obtained with the nasapower R package (Sparks 2018) using the
AG (agroclimatology) community. This package allows the downloading of data from the NASA POWER (National Aeronautics and Space Administration Prediction Of Worldwide Energy Resource) database, which is freely available for download. Climatic monthly and annual data (30-year period: Jan. 1984 Dec. 2013) of temperature at two meters $\left(\mathrm{T},{ }^{\circ} \mathrm{C}\right)$, precipitation (P, $\mathrm{mm} /$ day), and wind speed at $10 \mathrm{~m}(\mathrm{~W}$, $\mathrm{m} / \mathrm{s}$ ) were obtained for the coordinates in the center of each grid cell. To account for season variation of the variables across the year, mean values of climatic variables during the rainy (September to April; end of winter to the beginning of autumn; (de Sá Júnior et al. 2012) and dry (May to August; middle of autumn to middle of winter; (de Sá Júnior et al. 2012) seasons were calculated to obtain mean temperature $\left(\mathrm{T}_{\text {rainy }}\right.$ and $\left.\mathrm{T}_{d r y}\right)$, mean precipitation $\left(\mathrm{P}_{\text {rainy }}\right.$ and $\left.\mathrm{P}_{d r y}\right)$, and mean wind speed $\left(\mathrm{W}_{\text {rainy }}\right.$ and $\left.\mathrm{W}_{d r y}\right)$ during the rainy and dry season in Minas Gerais.

Predictor variables. The candidate variables for modeling were the log-transformed mean orchard 
area (A), the log-transformed number of mandarin and orange orchards ( $\mathrm{N}_{\text {mandarins }}$ and $\left.\mathrm{N}_{\text {orange }}\right), \mathrm{T}_{\text {rainy }}, \mathrm{T}_{\text {dry }}$, $\mathrm{P}_{\text {rainy }}, \mathrm{P}_{\text {dry }}, \mathrm{W}_{\text {rainy }}, \mathrm{W}_{\text {dry, }}$ mean annual wind speed $\left(\mathrm{W}_{\text {annual }}\right)$, temperature $\left(\mathrm{T}_{\text {annual }}\right)$, and precipitation ( $\left.\mathrm{P}_{\text {annual }}\right)$. Subsequently, only a subset of these variables was used in the modeling procedure, described below in "model selection".

Additionally, principal component analysis (PCA) using the variables described above was applied. This method was used to combine multiple covariates into a reduced number of uncorrelated principal components (PCs) and use them as model predictors. To account for different metrics across different variables, the PCA was performed based on the correlation matrix, in which the correlation of each variable with the PCs was expressed by a rotation with the Varimax method (Cendoya et al. 2020). The first three PCs were used as candidate predictors.

\section{Spatial modeling}

A Bayesian hierarchical approach, similar to a study to model Xylella fastidiosa spatial distribution in Spain and Italy (Cendoya et al. 2020), was used in our work. The integrated nested Laplace approximations (INLA) computation method was used to obtain posterior probabilities distributions of the model's parameter and hyperparameters, performed using the inla() function from the R package INLA (Rue et al. 2009).

The spatial model used was a reparametrization of the BYM-model (Besag York Mollié model) (Besag et al. 1991), which is a model commonly used in disease mapping (Simpson et al. 2017). The objective is to model the observed HLB prevalence (fraction of HLBpresent orchards) $y_{i}$ in a grid cell $i$, where $i=1, \ldots, G$, being $G$ the number of grid cells. In our study $y_{i}$ is assumed to follow a binomial distribution i.e., $y_{i} \sim$ $\operatorname{Binomial}\left(n_{i}, \pi_{i}\right)$, where $n_{i}$ is the number of orchards in a grid cell and $\pi_{i}$ is the probability of an orchard being HLB-present. The original BYM-model is given by $\eta_{i}=\beta_{0}+X_{i} \beta_{m}+u_{i}+v_{i}$, where $\beta_{0}$ is the overall intercept, $\beta_{m}$ is the effect of the covariates (or predictors) $\left(m=1, \ldots, N_{m}, N_{m}\right.$ is the number of covariates), $u_{i}$ is a zero-mean Gaussian with a precision matrix representing the unstructured random effect, and $v_{i}$ is the random effects spatial component that accounts for the similarities of the neighboring grid cells (Besag 1974; Besag et al. 1991; Simpson et al. 2017; Cendoya et al. 2020). The reparameterized model (Equation 1) adds $v_{i}{ }^{*}$, which is the scaled spatially structured component (Simpson et al. 2017)
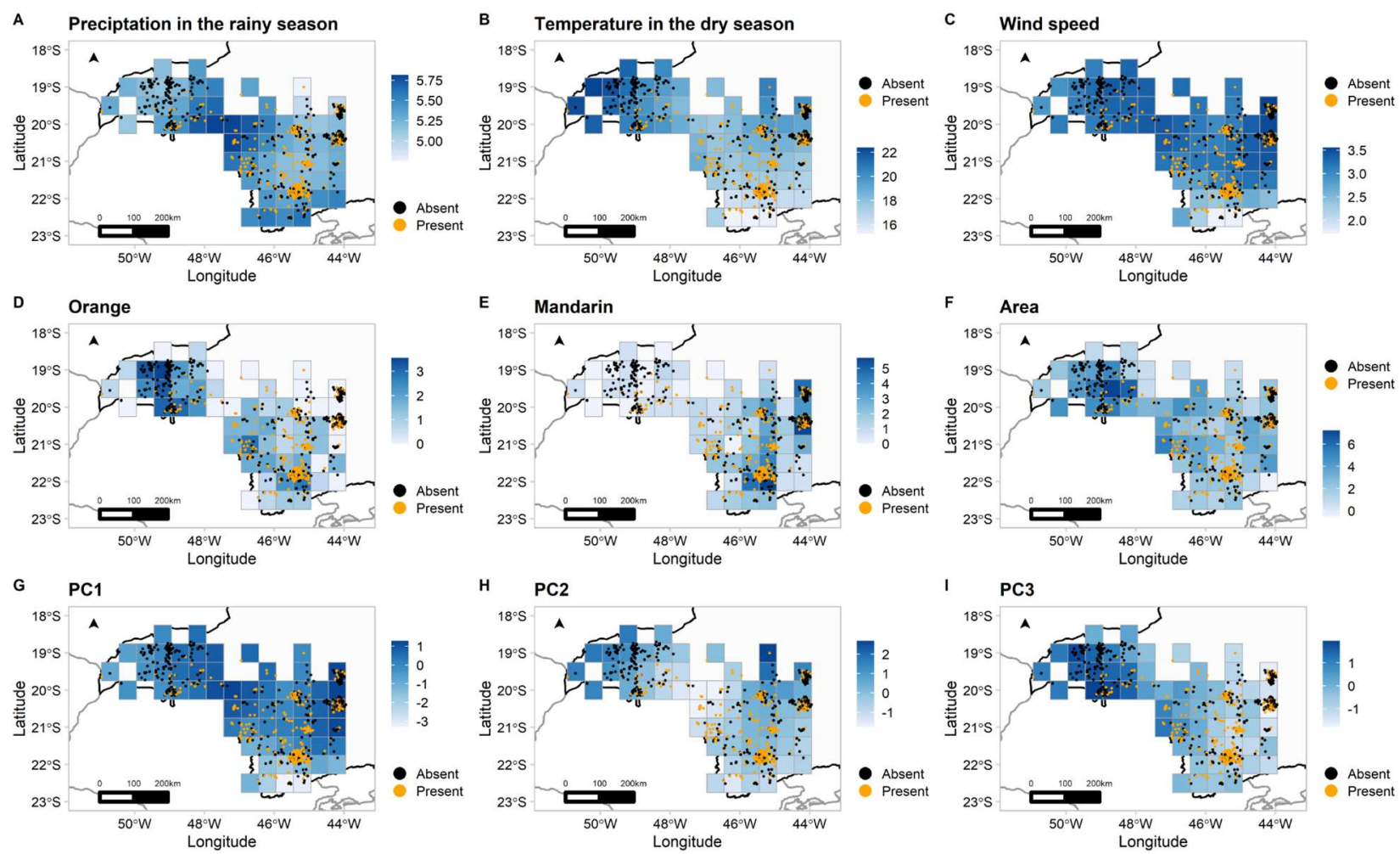

Figure 2: Candidate variables used for modeling the spatial distribution of citrus huanglongbing Minas Gerais. The candidate variables tested in the hierarchical Bayesian model using climate variables were mean precipitation during the rainy season (A), mean temperature during the dry season (B), and annual wind speed (C), log-transformed number mandarin (D) and orange orchards (E) log-transformed area (F). The candidate variables tested in hierarchical Bayesian models using principal components as covariates were the first three principal components (G, H, and I) of all 12 original variables. 


$$
\eta_{i}=\beta_{0}+X_{i} \beta_{m}+\frac{1}{\tau}\left(\sqrt{1-\phi} u_{i}+\sqrt{\phi} v_{i}^{*}\right)
$$

where $1 / \tau$ is the marginal precision contribution for $u_{i}$ and $v_{i}{ }^{*}$. The mixing parameter $\phi(0 \leq \phi \leq 1)$, is the fraction of the variance explained by the spatial structure, represented by $u_{i}$ and $v_{i}{ }^{*}$. Higher values of $\phi$ indicate high dependence on the spatial component. $X_{i}$ represents the vector of covariates. For more details about the reparameterized BYMmodel, see Simpson et al. (2017).

As described above, the spatial grid used to aggregate HLB spatial data was defined as $0.5 \times 0.5$ decimal degrees. In order to obtain all grid cells with at least one neighboring cell, we converted grid coordinates to Universal Transverse Mercator (UTM), and consider them as neighbor grid cells to those in a maximum distance range of $100 \mathrm{~km}$. Coordinates were transformed to UTM using the spTransform() function from the $R$ (R Core Team 2021) package sp (Bivand et al. 2013).

The full model and respective priors for model parameter and hyperparameters are given below:

$$
\begin{aligned}
& \eta_{i}=\beta_{0}+X_{i} \beta_{m}+\frac{1}{\tau}\left(\sqrt{1-\phi u_{i}}+\sqrt{\phi v_{i}^{*}}\right) \\
& y_{i} \sim \operatorname{Binomial}\left(n_{i}, \pi_{i}\right), i=1, \ldots, G \\
& \operatorname{logit}\left(\pi_{i}\right)=\beta_{0}+X_{i} \beta_{m}+\frac{1}{\tau}\left(\sqrt{1-\phi u_{i}}+\sqrt{\phi v_{i}^{*}}\right) \\
& P\left(\beta_{0}\right) \propto 1 \\
& \beta_{m} \sim N\left(\mu=0, \tau=10^{-3}\right), m=1, \ldots, N_{\beta} \\
& \tau \sim \operatorname{PCprior}(0.5 / 0.31,0.01), \\
& \phi \sim \operatorname{PCprior}(0.5,2 / 3)
\end{aligned}
$$

Where PCprior (') defines penalized complexity priors for the hyperparameters (Besag
1974; Besag et al. 1991; Simpson et al. 2017; Cendoya et al. 2020).

\section{Model selection}

To identify the best candidate models, a total of $2^{13}$ models would need to be tested (where 13 is the total number of covariates plus the spatial random effect) resulting in a total of 8,192 models, which would require a long time and computational cost. To reduce the number of covariates and avoid multicollinearity, Pearson's correlations were performed among all candidate predictors. If the absolute correlation coefficient $|r|$ value was higher than 0.7 , one of the variables was removed from subsequent analysis. Variables that passed this stage were used in the modeling procedure, in which $2^{k}$ models (where $k$ is the number of predictor variables including the spatial effect) were fitted and the Watanabe Akaike information criterion (WAIC; Watanabe, 2010) and the logarithmic conditional predictive ordinate (LCPO; Pettit, 1990) were calculated. Models with lower WAIC and LCPO values were selected.

\section{Data and code availability}

All data tidying and exploratory analysis (including maps) presented in this study were conducted using packages available in the tidyverse package (Wickham et al. 2019). All modeling procedures, downloading of climate data, and graphical work were done using $\mathrm{R}$ version 4.0.2 ( $\mathrm{R}$ Core Team 2021), the code was fully annotated using $\mathrm{R}$ markdown (Xie et al. 2018) to enable reproducibility. All files (data and codes) used in this study were organized as a research compendium stored in the Open Science Framework and can be freely accessed for download at osf.io/nyvak.

Table 1: Mean, Median, standard deviation (SD), 95\% highest posterior density (HPD) interval, and mode of model parameters and hyperparameters of the best model with climate covariates for citrus Huanglongbing prevalence distribution in Minas Gerais, Brazil.

\begin{tabular}{lcccccc}
\hline Parameters & Mean & Median & SD & HPD $_{\text {lower }}$ & HPD $_{\text {upper }}$ & Mode \\
\hline$\beta_{0}$ & 1.244 & 1.245 & 8.309 & -15.241 & 17.618 & 1.270 \\
$\mathrm{P}_{\text {rainy }}$ & 1.264 & 1.264 & 1.198 & -1.102 & 3.625 & 1.263 \\
${ }^{*} \mathrm{~T}_{\text {dry }}$ & -0.670 & -0.666 & 0.211 & -1.090 & -0.257 & -0.660 \\
${ }^{*} \mathrm{~W}_{\text {annual }}$ & 1.330 & 1.317 & 0.673 & 0.016 & 2.661 & 1.293 \\
\hline Hyperparameters & Mean & Median & SD & HPD $_{\text {lower }}$ & HPD $_{\text {upper }}$ & Mode \\
\hline$\tau$ & 0.678 & 0.652 & 0.194 & 0.339 & 1.064 & 0.603 \\
$\phi$ & 0.141 & 0.090 & 0.146 & $8.470 \times 10^{-6}$ & 0.451 & 0.010 \\
\hline
\end{tabular}

*Significant coefficients (95\% HPD interval excludes 0). 


\section{Results}

\section{Climate covariates (CC) model}

The variables selected on the $|r| \leq 0.7$ threshold between each other were the logtransformed area (A), log-transformed number mandarin and orange orchards ( $\mathrm{N}_{\text {mandarins }}$ and $\left.\mathrm{N}_{\text {orange }}\right)$, mean temperature during the dry season $\left(\mathrm{T}_{d r y}\right)$, mean precipitation during the rainy season $\left(\mathrm{P}_{\text {rainy }}\right)$, and annual wind speed $\left(\mathrm{W}_{\text {annual }}\right)$. Distribution of values for these variables ranged from -0.51 to 7.24 (A), 0 to 5.69 ( $\left.\mathrm{N}_{\text {mandarins }}\right), 0$ to 3.55 ( $\left.\mathrm{N}_{\text {orange }}\right), 4.75 \mathrm{~mm} /$ day to 5.81 $\mathrm{mm} /$ day $\left(\mathrm{P}_{\text {rainy }}\right), 15.26{ }^{\circ} \mathrm{C}$ to $22.39^{\circ} \mathrm{C}\left(\mathrm{T}_{\text {dry }}\right)$, and $1.72 \mathrm{~m} / \mathrm{s}$ to $3.56 \mathrm{~m} / \mathrm{s}\left(\mathrm{W}_{\text {annual }}\right)$. The spatial distribution maps of the orchard-related and climatic variables are depicted in Figure 2.

As six variables (A, $\mathrm{N}_{\text {mandarins }}, \mathrm{N}_{\text {orange }}, \mathrm{T}_{\text {dry }}, \mathrm{P}_{\text {rainy }}$ and $\left.\mathrm{W}_{\text {annual }}\right)$ and the spatial effect were selected, the number of models evaluated combining all variables was $2^{7}$, resulting in a total of 128 models. The model with lower WAIC (215.678) and LCPO (1.421) was the model that combined the $P_{\text {rainy }}, \mathrm{T}_{\text {dry }}, \mathrm{W}_{\text {annual, }}$ and random spatial effect. Besides the mean of the posterior distribution of the effect parameter for $P_{\text {rainy }}$ being positive, its $95 \%$ highest probability density
(HPD, values ranging between $\mathrm{HPD}_{\text {lower }}$ and $\mathrm{HPD}_{\text {upper }}$ ) interval contains zero, therefore the parameter was not significant (Table 1).

The mean of the posterior distribution for the effect of $\mathrm{T}_{\text {dry }}$ was negative (Table 1), and its HPD interval does not contain zero, therefore, a significant effect, indicating a lower probability of HLB-presence in regions with high temperatures during the dry season and vice versa. The posterior mean for the parameter of $\mathrm{W}_{\text {annual }}$ was positive and significant (Table 1), indicating the HLB-presence is more likely in regions in which wind speeds are higher.

The mean of the posterior distribution for mixing parameter $\phi$ was 0.141 indicating a partial influence of the spatial effect on the HLB-presence probability (Table 1). The spatial distributions of the posterior mean and standard deviation of the spatial effect are depicted in Figures 3A and 3B, respectively. The posterior mean of the spatial effect ranged from -2.68 to 2.06 across the grid, while the posterior standard deviation ranged from 0.36 to 1.68 across the grid. Higher posterior mean values for the spatial effect indicate a higher probability of HLB presence.

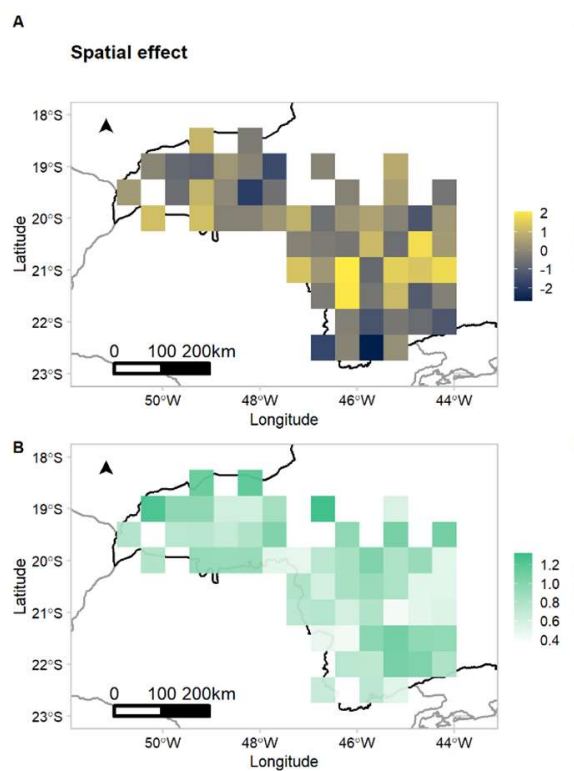

c

HLB risk

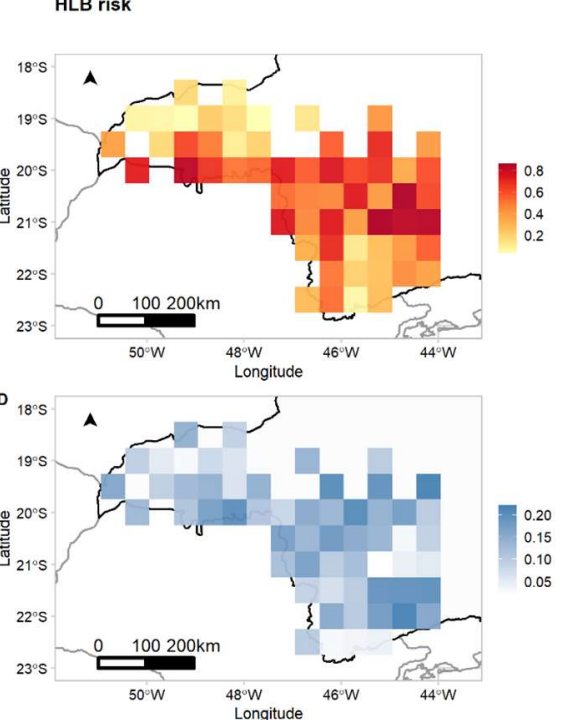

E

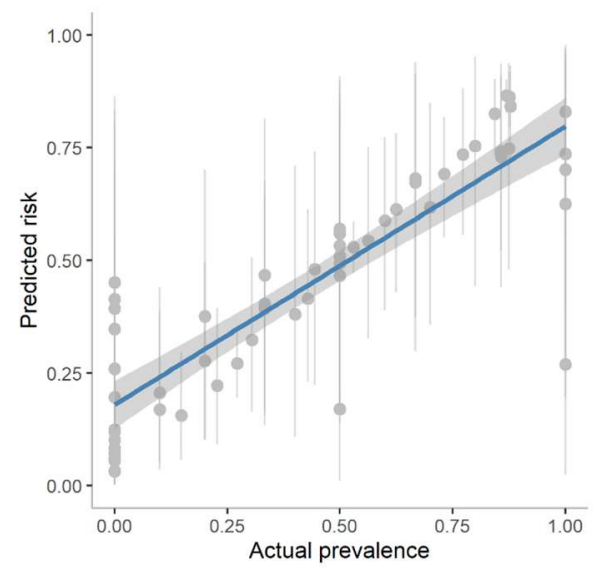

Figure 3: Model with climate covariates and the spatial effect. The maps on the left depict the mean (A) and standard deviation (B) of the posterior distribution of spatial effect. The maps in the middle depict the posterior mean (C) and standard deviation (D) of the spatial distribution of HLB prevalence or risk in Minas Gerais using the climate covariate model with mean daily precipitation during the rainy season $\left(P_{\text {rainy }}\right)$, mean temperature during the dry season $\left(T_{d r y}\right)$, mean annual wind speed ( $W_{\text {annual }}$ ), and the spatial effect as covariates. In the right $(E)$ is shown the relationship between actual prevalence and the posterior mean (dots) and $95 \%$ highest posterior density (error bars) obtained with the climate covariate model. 


\section{Principal components (PC) model}

The three first principal components obtained in the PCA explained $81.1 \%$ of the total cumulative variation in the data (Table 2). The percentage of variance explained by the first, second, and third principal components were $30.7 \%, 28.4 \%$, and $22.0 \%$, respectively. Wind speed-related variables contributed the highest to the first principal component (PC1), with coefficients above 0.88 , where $\mathrm{W}_{\text {rainy }}$ contributed 0.974 to $\mathrm{PC}$. In the second principal component (PC2), $\mathrm{P}_{\text {annual }}$ had the highest absolute contribution, with an estimated coefficient of -0.884. In the third principal component (PC3), $\mathrm{T}_{\text {rainy }}$ was the variable with the highest contribution, with a coefficient value of 0.660 (Table 2). Maps with the spatial distribution of each principal component were produced, but it was not possible to visualize a clear relationship between values and HLB presence (Figure 2G, 2H, and 2I).

Table 2: Loading of the first three principal components (PC1, PC2, and PC3) from the principal component analysis using the climatic and orchardrelated variables.

\begin{tabular}{cccc}
\hline Variable & PC1 & PC2 & PC3 \\
\hline$A$ & 0.244 & -0.147 & 0.653 \\
$N_{\text {mandarin }}$ & & & -0.630 \\
$N_{\text {orange }}$ & -0.164 & & 0.649 \\
$P_{\text {annual }}$ & -0.279 & -0.884 & 0.238 \\
$P_{\text {dry }}$ & -0.739 & -0.566 & \\
$P_{\text {rainy }}$ & & -0.872 & 0.297 \\
$T_{\text {annual }}$ & 0.292 & 0.689 & 0.621 \\
$T_{\text {dry }}$ & 0.383 & 0.716 & 0.537 \\
$T_{\text {rainy }}$ & 0.237 & 0.666 & 0.660 \\
$W_{\text {annual }}$ & 0.974 & 0.154 & 0.115 \\
$W_{\text {dry }}$ & 0.883 & 0.219 & 0.364 \\
$W_{\text {rainy }}$ & 0.974 & 0.109 & \\
\hline Variance (\%) & 30.7 & 28.4 & 22.0 \\
Cumulative var. $(\%)$ & 30.7 & 59.1 & 81.1 \\
\hline
\end{tabular}

Using only the three first principal components and the spatial effect, the number of models evaluated was a total of 16 models (equivalent to $\left.2^{4}\right)$. The model with the lowest WAIC (214.503) and a moderate LCPO value (6.35) was the model developed from PC1 and PC2 plus the spatial effect.

The mean of the posterior distribution of the parameter for PC1 was positive, but not significant since the HPD interval contains zero (Table 3). However, the mean of the posterior distribution of the parameter for PC2 was negative and significant (Table
3). The mean of the posterior distribution of the mixing parameter $\phi$ was slightly higher than that of the model with climate covariates but also indicating a partial effect of the spatial effect on HLB presence (Table 3). The across-grid mean and standard deviation of the posterior distribution of the spatial effect is depicted in Figures 3A and 3B. Mean values ranged from -2.39 to 2.41 , while standard deviation ranged from 0.35 to 1.65

The posterior mean of HLB prevalence in MG ranged from 0.035 to 0.865 . The highest values are also in a region with a high density of orchards in the eastern region of the grid (Figure 4C). Lower posterior probabilities were located in peripheral regions over western and southern Minas Gerais. The posterior standard deviation of the probabilities ranged from 0.019 to 0.223 , and its spatial distribution was very similar to the model with climate covariates (Figure $4 \mathrm{D})$. Overall, there was a high correlation between the mean risk and actual HLB prevalence (Figure 4E), in which the estimated coefficient of determination $\left(\mathrm{r}^{2}\right)$ was 0.75 , which indicates high model precision. In fact, the mean HLB-risk predicted by both models presented here had a strong positive correlation between themselves (Pearson's $r=0.99$ ).

\section{Discussion}

Using two different modeling approaches, climate-driven models were successfully fitted to regional HLB prevalence at an important sweetorange and mandarin-production region of Brazil. Among several climatic variables, the normal temperature during the dry season and annual wind speed were selected as the most significant variables to explain the spatial distribution of HLB prevalence through the climate covariates (CC) model. In contrast, the principal components (PC) model also suggested temperature as a key factor and included mean annual and rainy season precipitation as important variables. Both models suggested a partial spatial effect, although the CC model accounted for more than that reported in the PC model. Both models performed with high precision and provided comparable HLB predictions between them. Our findings are in general agreement with the current knowledge of factors that affect HLB epidemics. Models suggested an inverse relationship between temperatures during the dry (winter) period and HLB development and spread, whereas wind speed was directly associated with a greater likelihood of HLB development. In the PC model, increased mean annual and rainy season precipitation would increase HLB prevalence. 
Table 3: Mean, Median, standard deviation (SD), $95 \%$ highest posterior density (HPD) interval, and mode of model parameters and hyperparameters of the best model with principal components as covariates for citrus huanglongbing prevalence distribution in Minas Gerais, Brazil.

\begin{tabular}{lcccccc}
\hline Parameters & Mean & Median & SD & HPD $_{\text {lower }}$ & HPD $_{\text {upper }}$ & Mode \\
\hline$\beta_{0}$ & -0.396 & -0.391 & 0.207 & -0.808 & 0.006 & -0.383 \\
$\mathrm{PC} 1$ & 0.036 & 0.034 & 0.212 & -0.379 & 0.455 & 0.029 \\
$\star \mathrm{PC} 2$ & -0.895 & -0.891 & 0.252 & -1.394 & -0.405 & -0.882 \\
\hline Hyperparameters & Mean & Median & SD & HPD $_{\text {lower }}$ & HPD $_{\text {upper }}$ & Mode \\
\hline$\tau$ & 0.623 & 0.602 & 0.169 & 0.324 & 0.959 & 0.562 \\
$\phi$ & 0.172 & 0.128 & 0.148 & 0.002 & 0.482 & 0.033 \\
\hline
\end{tabular}

*Significant coefficients (95\% HPD interval excludes 0).

During May to August (autumn and winter months), low to no-host flushing occurs, as a result, lower D. citri densities have been suggested and a reduced risk of HLB can be expected (Gutierrez and Ponti 2013; Lewis-Rosenblum et al. 2015; Teck et al. 2011; Hall and Albrigo 2007). The climate normal of winter temperatures across the area of study, for the 30-year period considered, ranged between 15 and 22 ${ }^{\circ} \mathrm{C}$, and a higher frequency of $18{ }^{\circ} \mathrm{C}$ and greater was recorded (data not shown). Multiple studies identified mild $\left(17 / 22{ }^{\circ} \mathrm{C}\right)$ to hot $\left(32-50{ }^{\circ} \mathrm{C}\right)$ temperatures as detrimental to CLas replication and survival (Gasparoto et al. 2012; Razi et al. 2014; Lopes et al. 2009). In agreement with the above findings, our study suggests that mean winter temperatures are inversely related to HLB prevalence in Minas Gerais, suggesting that in regions where temperatures are higher during the winter, the conditions somehow may be detrimental to CLas. However, recently, Lopes et al. (2017) reported temperatures below $15{ }^{\circ} \mathrm{C}$ favored CLas titer in flushes of symptomatic trees, which had a lower frequency of occurrence across the region of this study. Additionally, authors speculated drier periods were associated with host trees experiencing water deficiency reducing tissue availability for D. citri feeding and reproduction, potentially supporting the dry season reported in our model.

Long and short-distance dispersal of CLas is dependent on the dissemination of D. citri (Martini et al. 2018; Tomaseto et al. 2018; Antolinez et al. 2021; Lewis-Rosenblum et al. 2015). Tomaseto et al. (2018) posited at $27.14{ }^{\circ} \mathrm{C}, \sim 50 \%$ of adult D. citri will initiate flight. Although Martini et al. (2018) stated wider temperature ranges, 18 to $28{ }^{\circ} \mathrm{C}$, lengthened D. citri flight duration and distance. Recently, a decline in flight and no long-distance flight initiation was observed at temperatures greater than $32{ }^{\circ} \mathrm{C}$ and 43 ${ }^{\circ} \mathrm{C}$, respectively (Antolinez et al. 2021). These findings are in agreement with our results in relation to the inverse effect of temperature on HLB prevalence, mostly because the decrease in temperature might act as a chief stimulus that influences psyllid movement responses, which is one of the main forms of CLas long-distance dispersal.

Adult psyllids are responsible for the spreading of CLas, whereas, D. citri nymphs are known for greater acquisition efficiency, as well as faster CLas replication (George 2018; Ammar et al. 2016; Gottwald 2010). The voluntary and involuntary movement of adult psyllids is associated with wind speed and direction (Carmo-Sousa et al. 2020). The mean annual wind speed in MG ranged between 6.19 to $12.8 \mathrm{~km} / \mathrm{h}$. The increase of wind speed in wind tunnels has been suggested to be directly associated with the involuntary movement of psyllids (Martini et al. 2018). These results support our thesis that the increase in wind speed is directly associated with HLB prevalence, which is due to a greater probability of movement by psyllids, thus greater risk of HLB establishment and spread. However, the elucidation of optimal wind speed for flight initiation and termination may assist in understanding D. citri movement, and concomitant CLas spread.

Furthermore, our study did not include wind direction, although Antolinez et al. (2021) suggest the inclusion of wind direction to be critical in understanding the effect of wind on flight orientation. Therefore, the contribution of wind direction to the partial spatial component to the $\mathrm{CC}$ model may be speculated. 
Although adult psyllids are capable of acquiring CLas, the acquisition time required is much longer, impacting on the temporal as well as spatial contributions to pathogen spread and prevalence (Ammar et al. 2016). The reduced contribution of the partial spatial effect may be a result of predominant adult $D$. citri movement occurring during the spring and summer months, i.e., MG rainy season, resulting in greater pathogen dissemination through vector dispersal during this period (Lewis-Rosenblum et al. 2015b; George 2018). Another explanation to the reduced spatial effect is the long between-cell distance $(100 \mathrm{~km})$ used to create the spatial grid structure for modeling.

Although the interpretation of specific effects of individual variables when using PCs as covariates during a modeling procedure might be complicated (Cendoya et al. 2020), the PC model allows for the conjecture to be made that greater rainfall in both the annual and rainy season result in a greater risk of HLB. Whereas, warmer winters are associated with periods of reduced disease favorability conditions, lowering the probability of HLB events, similar to that of the CC model. Although, in the PC model, rainfall had a higher influence than the temperature on HLB risk, due to the PC2 contributions.

Rainfall is highly associated with host physiology and in turn, D. citri population dynamics.
Greater populations of psyllid adults were associated with wet summer periods where greater flush tissue is available (Shimwela et al. 2018; Tsai et al. 2002; Lewis-Rosenblum et al. 2015; Gutierrez and Ponti 2013; Narouei-Khandan et al. 2016). Through multiple regression, rainfall coincided with flush availability, one in the wet season and the second in the dry season, and was significantly associated with favoring greater CLas titer in symptomatic flushes (Lopes et al. 2017). Our results corroborate these findings, like a greater risk of HLB is associated with higher annual and wet season rainfall.

Sampling and quantifying CLas titer of symptomatic trees (i.e., when flushes are present) or trapping psyllids in areas predicted to have a higher prevalence of HLB, could confirm our model assumption. Furthermore, oviposition and nymphal development occur exclusively on young flushes (Hall et al. 2008). The risk for CLas acquisition by nymphs is greater and faster than in adults, as a result the probability for transmission to neighboring hosts once D. citri mature, is possible (Pelz-Stelinski et al. 2010; George 2018; Ammar et al. 2016; Gottwald 2010). Rainfall should be included as a regional risk assessment parameter, potentially maximizing management strategies already in place.
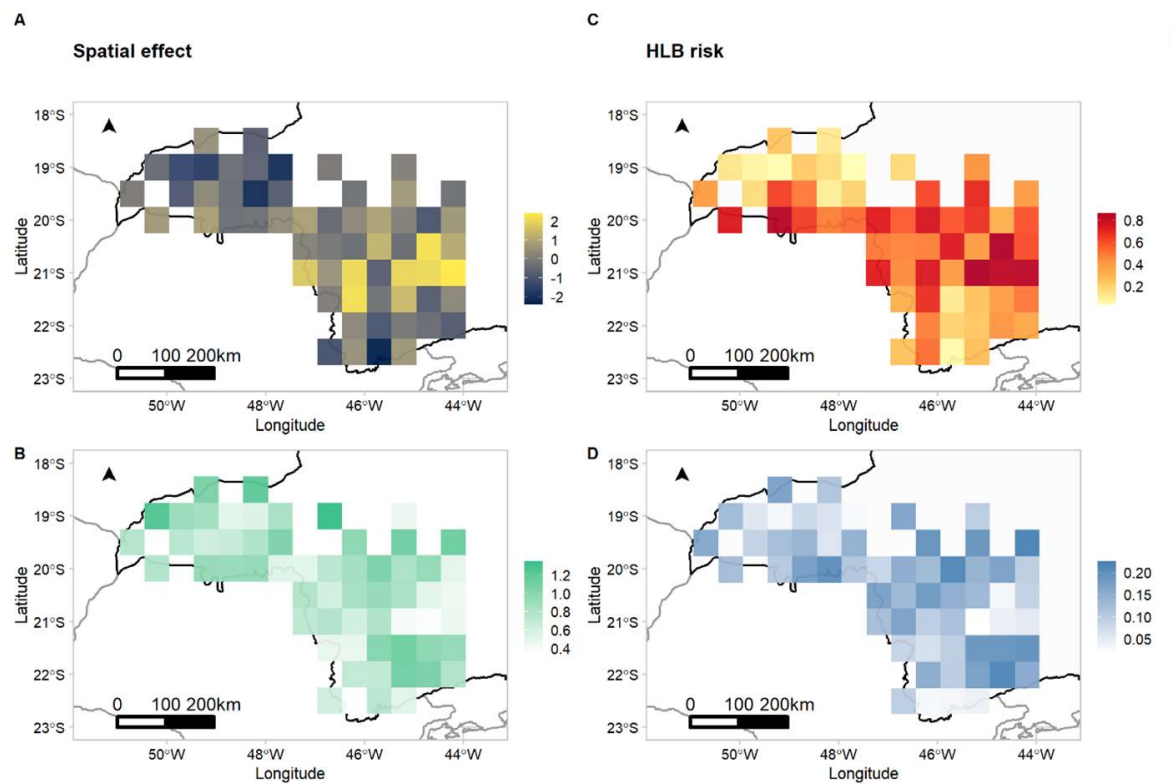

Figure 4: Model with principal components and the spatial effect. The maps on the left depict the mean (A) and standard deviation (B) of the posterior distribution of spatial effect. The maps in the middle depict the posterior mean (C) and standard deviation (D) of the spatial distribution of HLB prevalence or risk in Minas Gerais obtained using the model with the second and third principal components (PC2 and PC3) and the spatial effect as covariates. In the right (E) is shown the relationship between actual prevalence and the posterior mean (dots) and $95 \%$ highest posterior density (error bars) obtained with the principal components model. 
We speculate that areas closer to HLB orchards will more likely be infected than those farther away, suggesting a clustering or coalescence of HLB events, although the spatial effect was only partial. In this study, orchards adjacent to the São Paulo state would have a high probability for the presence of HLB, contrasting to areas in the northwest and south of MG, where lower posterior mean probabilities were obtained. As CLas was first reported in $\mathrm{SP}$, the result may have been expected to some extent (Coletta-Filho et al. 2004; do Carmo Teixeira et al. 2005. Consequently, a previous study by Alves et al. (2020) indicated a greater spread of HLB in the regions bordering SP than those in central and south MG. Furthermore, CLas positive psyllids were in higher populations in southwestern and northern SP, compared to the state border between MG and SP (Wulff et al. 2020). Combining the findings of Alves et al. (2020) and Wulff et al. (2020) one can speculate the support of results for this border effect in orchards of the current study.

Furthermore, the posterior mean of the mixing parameter of each model accounted for less than 0.5 , therefore the spatial effect does not explain the majority of variance of the response variable. The age of an orchard, associated with flushing and psyllid feeding preference, and the psyllid population dynamics, drive the spatial and temporal progress of HLB through the availability of viable inoculum (Bassanezi et al. 2013). Orchard age and epidemiologically competent psyllid population data were not collected during the surveys and as such were not included in model development, potentially contributing to the lack of spatial effect contribution.

The models presented could motivate targeted monitoring in regions with higher HLB risk, focusing on orchards between poorly managed areas and newly planted or younger orchards. Furthermore, scouting in higher-risk regions for Citrus spp., in backyards, public gardens, pasture, and forests may also contribute to mitigating HLB through eradicating and replacing these trees (Bassanezi et al. 2013). Management strategies should consider the climatic effects when timing vector control intervention, in order to manage CLas titer within orchards associated with higher HLB risk, enhancing area-wide management in place.

\section{Acknowledgments}

K.S.A. acknowledges the CAPES for providing a graduate scholarship. EMD is thankful to Conselho Nacional de Desenvolvimento Científico e Tecnológico (CNPq) for providing a research fellowship. Climatic data were obtained from the NASA Langley Research Center POWER Project funded through the NASA Earth Science Directorate Applied Science Program.

\section{Literature Cited}

Alves, K. S., do Carmo, L. H. M., and Del Ponte, E. M. 2020. Spatiotemporal spread of huanglongbing in commercial citrus orchards of Minas Gerais, Brazil. Trop. Plant Pathol. 45:668679.

Ammar, E.-D., Ramos, J. E., Hall, D. G., Dawson, W. O., and Shatters, R. G. 2016. Acquisition, Replication and Inoculation of Candidatus Liberibacter asiaticus following Various Acquisition Periods on Huanglongbing-Infected Citrus by Nymphs and Adults of the Asian Citrus Psyllid ed. Murad Ghanim. PLOS ONE. 11:e0159594 Available at: https://dx.plos.org/10.1371/journal.pone.0159594 [Accessed October 2, 2020].

Antolinez, C. A., Moyneur, T., Martini, X., and Rivera, M. J. 2021. High Temperatures Decrease the Flight Capacity of Diaphorina citri Kuwayama (Hemiptera: Liviidae). Insects. 12:394 Available at: https://www.mdpi.com/20754450/12/5/394 [Accessed May 4, 2021].

Bassanezi, R. B., Busato, L. A., Filho, A. B., Amorim, L., and Gottwald, T. R. 2005. Preliminary spatial pattern analysis of Huanglongbing in São Paulo, Brazil. Int. Organ. Citrus Virol. Conf. Proc. 1957-2010. 16 Available at: https://escholarship.org/uc/item/76s629f9\#author [Accessed April 12, 2021].

Bassanezi, R. B., Lopes, S. A., de Miranda, M. P., Wulff, N. A., Volpe, H. X. L., and Ayres, A. J. 2020. Overview of citrus huanglongbing spread and management strategies in Brazil. Trop. Plant Pathol. 45:251-264.

Bassanezi, R. B., Montesino, L. H., Gimenes-Fernandes, N., Yamamoto, P. T., Gottwald, T. R., Amorim, L., et al. 2013. Efficacy of Area-Wide Inoculum Reduction and Vector Control on Temporal Progress of Huanglongbing in Young Sweet Orange Plantings. Plant Dis. 97:789-796.

Besag, J. 1974. Spatial Interaction and the Statistical Analysis of Lattice Systems. J. R. Stat. Soc. Ser. B Methodol. 36:192-225.

Besag, J., York, J., and Mollié, A. 1991. Bayesian image restoration, with two applications in spatial statistics. Ann. Inst. Stat. Math. 43:1-20.

Bivand, R. S., Pebesma, E., and Gomez-Rubio, V. 2013. Applied spatial data analysis with R, Second edition. Springer, NY. Available at: https://asdar-book.org/.

Bové, J. M. 2006. Huanglongbing: a destructive, newly-emerging, century-old disease of citrus. J. Plant Pathol. 88:7-37 Available at: https://www.jstor.org/stable/41998278 [Accessed October 2, 2020].

do Carmo Teixeira, D., Saillard, C., Eveillard, S., Danet, J. L., Costa P. I. da, Ayres, A. J., et al. 2005. 'Candidatus Liberibacter americanus', associated with citrus huanglongbing (greening disease) in São Paulo State, Brazil. Int. J. Syst. Evol. Microbiol. 55:1857-1862 Available at:

https://www.microbiologyresearch.org/content/journal/ijse m/10.1099/ijs.0.63677-0 [Accessed October 2, 2020].

Carmo-Sousa, M., Cortés, M. T. B., and Lopes, J. R. S. 2020. Understanding psyllid transmission of Candidatus Liberibacter as a basis for managing huanglongbing. Trop. Plant Pathol. Available at: https://doi.org/10.1007/s40858-020-00386-1 [Accessed October 2, 2020].

Carvalho, S. A. D., Girardi, E. A., Mourão Filho, F. D. A. A., Ferrarezi, R. S., \& Coletta Filho, H. D. 2019. Advances in citrus propagation in Brazil. Revista Brasileira de Fruticultura 41 (6). http://dx.doi.org/10.1590/0100-29452019422

Cendoya, M., Martínez-Minaya, J., Dalmau, V., Ferrer, A., Saponari, M., Conesa, D., et al. 2020. Spatial Bayesian Modeling Applied to the Surveys of Xylella fastidiosa in Alicante (Spain) and Apulia (Italy). Front. Plant Sci. 11 Available at: https://www.frontiersin.org/articles/10.3389/fpls.2020.0120 
4/full [Accessed August 24, 2020].

Coletta-Filho, H. D., Targon, M. L. P. N., Takita, M. A., De Negri, J. D., Pompeu, J., Machado, M. A., et al. 2004. First Report of the Causal Agent of Huanglongbing ("Candidatus Liberibacter asiaticus") in Brazil. Plant Dis. 88:1382-1382 Available at: https://apsjournals.apsnet.org/doi/abs/10.1094/PDIS.2004. 88.12.1382C [Accessed October 2, 2020].

Craig, A. P., Cunniffe, N. J., Parry, M., Laranjeira, F. F., and Gilligan, C. A. 2018. Grower and regulator conflict in management of the citrus disease Huanglongbing in Brazil: A modelling study. J. Appl. Ecol. 55:1956-1965 Available at: https://besjournals.onlinelibrary.wiley.com/doi/abs/10.1111/ 1365-2664.13122 [Accessed October 18, 2020].

Fundecitrus. 2019. Fundecitrus. Available at: https://www.fundecitrus.com.br/pdf/levantamentos/levant amento-doencas-2019.pdf [Accessed October 2, 2020].

Gasparoto, M. C. G., Coletta-Filho, H. D., Bassanezi, R. B., Lopes, S. A., Lourenço, S. A., and Amorim, L. 2012. Influence of temperature on infection and establishment of 'Candidatus Liberibacter americanus' and 'Candidatus Liberibacter asiaticus' in citrus plants. Plant Pathol. 61:658-664 Available at: https://bsppjournals.onlinelibrary.wiley.com/doi/abs/10.1111 /j.1365-3059.2011.02569.x [Accessed October 25, 2020].

Gasparoto, M. C. G., Hau, B., Bassanezi, R. B., Rodrigues, J. C., and Amorim, L. 2018. Spatiotemporal dynamics of citrus huanglongbing spread: a case study. Plant Pathol. 67:1621-1628.

George, J. 2018. Prolonged phloem ingestion by Diaphorina citri nymphs compared to adults is correlated with increased acquisition of citrus greening pathogen. Sci. Rep. :11.

Gottwald, T., Irey, M., Gast, T., Parnell, S., Taylor, E., Hilf, M., et al. 2010. Spatio-temporal Analysis of an HLB Epidemic in Florida and Implications for Spread.

Gottwald, T. R. 2010. Current epidemiological understanding of citrus huanglongbing. Annu. Rev. Phytopathol. :119-139 Available at:

https://pubag.nal.usda.gov/download/47697/PDF [Accessed October 10, 2020].

Gutierrez, A. P., and Ponti, L. 2013. Prospective Analysis of the Geographic Distribution and Relative Abundance of Asian Citrus Psyllid (Hemiptera: Liviidae) and Citrus Greening Disease in North America and the Mediterranean Basin. Fla. Entomol. 96:1375-1391.

Hall, D. G., and Albrigo, L. G. 2007. Estimating the Relative Abundance of Flush Shoots in Citrus with Implications on Monitoring Insects Associated with Flush. HortScience. 42:364-368 Available at:

https://journals.ashs.org/view/journals/hortsci/42/2/articl e-p364.xml [Accessed May 4, 2021].

Hall, D. G., Hentz, M. G., and Adair, R. C., Jr. 2008. Population Ecology and Phenology of Diaphorina citri (Hemiptera: Psyllidae) in Two Florida Citrus Groves. Environ. Entomol. 37:914-924 Available at: https://doi.org/10.1093/ee/37.4.914 [Accessed May 9, 2021].

Instituto Brasileiro De Geografia E Estatística - IBGE. 2018. Levantamento Sistemático da Produção Agrícola. Disponível em: https://www.ibge.gov.br/estatisticasnovoportal/economicas/agricultura-e-pecuaria/9201levantamento-sistematico-da-producaoagricola.html?et=resultados.

Jagoueix, S., Bové, J.-M., and Garnier, M. 1994. The PhloemLimited Bacterium of Greening Disease of Citrus Is a Member of the a Subdivision of the Proteobacteria. Int. J. Syst. Bacteriol. :379-386.

Leal, R. M., Barbosa, J. C., Costa, M. G., Belasque Junior, J., Yamamoto, P. T., and Dragone, J. 2010. Distribuição espacial de Huanglongbing (Greening) em citros utilizando a geoestatística. Rev. Bras. Frutic. 32:808-818.

Lewis-Rosenblum, H., Martini, X., Tiwari, S., and Stelinski, L. L. 2015a. Seasonal Movement Patterns and Long-Range Dispersal of Asian Citrus Psyllid in Florida Citrus. J. Econ. Entomol.
108:3-10 Available at: https://doi.org/10.1093/jee/tou008 [Accessed April 12, 2021].

Lopes, S. A., Bassanezi, R. B., Jr, J. B., and Yamamoto, P. T. 2008 Management of Citrus Huanglongbing in the State of São Paulo-Brazil. Available at: https://www.fftc.org.tw/htmlarea_file/library/2011071 2174730/eb609.pdf.

Lopes, S. A., Bertolini, E., Frare, G. F., Martins, E. C., Wulff, N. A., Teixeira, D. C., et al. 2009. Graft Transmission Efficiencies and Multiplication of ' Candidatus Liberibacter americanus' and ' $\mathrm{Ca}$. Liberibacter asiaticus' in Citrus Plants. Phytopathology®. 99:301-306 Available at: https:// apsjournals.apsnet.org/doi/10.1094/PHYTO-99-3-0301 [Accessed October 25, 2020].

Lopes, S. A., Luiz, F. Q. B. F., Oliveira, H. T., Cifuentes-Arenas, J. C., and Raiol-Junior, L. L. 2017. Seasonal Variation of ' Candidatus Liberibacter asiaticus' Titers in New Shoots of Citrus in Distinct Environments. Plant Dis. 101:583-590 Available at: https://apsjournals.apsnet.org/doi/10.1094/PDIS-06-160859-RE [Accessed May 8, 2021].

Madden, L. V., Hughes, G., and van den Bosch, F. 2007. The Study of Plant Disease Epidemics. St. Paul: APS Press. Available at: https://apsjournals.apsnet.org/doi/book/10.1094/97808905 45058 [Accessed March 8, 2019].

Martini, X., Rivera, M., Hoyte, A., Sétamou, M., and Stelinski, L. 2018. Effects of Wind, Temperature, and Barometric Pressure on Asian Citrus Psyllid (Hemiptera: Liviidae) flight behavior. J. Econ. Entomol. 111:8.

Narouei-Khandan, H. A., Halbert, S. E., Worner, S. P., and van Bruggen, A. H. C. 2016. Global climate suitability of citrus huanglongbing and its vector, the Asian citrus psyllid, using two correlative species distribution modeling approaches, with emphasis on the USA. Eur. J. Plant Pathol. 144:655-670 Available at: http://link.springer.com/10.1007/s10658-0150804-7 [Accessed May 8, 2021].

Pelz-Stelinski, K. S., Brlansky, R. H., Ebert, T. A., and Rogers, M. E. 2010. Transmission Parameters for Candidatus Liberibacter asiaticus by Asian Citrus Psyllid (Hemiptera: Psyllidae). J. Econ. Entomol. 103:1531-1541 Available at: https://academic.oup.com/jee/articlelookup/doi/10.1603/EC10123 [Accessed May 9, 2021].

Pettit, L. I. 1990. The Conditional Predictive Ordinate for the Normal Distribution. J. R. Stat. Soc. Ser. B Methodol. 52:175184.

R Core Team. 2021. R: A Language and Environment for Statistical Computing. Vienna, Austria: R Foundation for Statistical Computing. Available at: https://www.R-project.org/.

Razi, M. F., Keremane, M. L., Ramadugu, C., Roose, M., Khan, I. A., and Lee, R. F. 2014. Detection of Citrus HuanglongbingAssociated ' Candidatus Liberibacter asiaticus' in Citrus and Diaphorina citri in Pakistan, Seasonal Variability, and Implications for Disease Management. Phytopathology®. 104:257-268 Available at: https://apsjournals.apsnet.org/doi/10.1094/PHYTO-08-130224-R [Accessed May 4, 2021].

Rue, H., Martino, S., and Chopin, N. 2009. Approximate Bayesian inference for latent Gaussian models by using integrated nested Laplace approximations. J. R. Stat. Soc. Ser. B Stat. Methodol. 71:319-392.

de Sá Júnior, A., de Carvalho, L. G., da Silva, F. F., and de Carvalho Alves, M. 2012. Application of the Köppen classification for climatic zoning in the state of Minas Gerais, Brazil. Theor. Appl. Climatol. 108:1-7 Available at:

https://doi.org/10.1007/s00704-011-0507-8 [Accessed Novem ber 16, 2020].

Passos, O. S., da Silva Souza, J., Costa Bastos, D., Girardi, E. A., de Lima Gurgel, F., Bastos Garcia, M. V., de Oliveira, R. P. and dos Santos Soares Filho, W. Citrus Industry in Brazil with Emphasis on Tropical Areas in Citrus-Health Benefits and Production Technology. IntechOpen, 2018. Available at: DOI: 
10.5772/intechopen.80213.

Shen, W., Halbert, S. E., Dickstein, E., Manjunath, K. L., Shimwela, M. M., and Bruggen, A. H. C. van. 2013. Occurrence and ingrove distribution of citrus huanglongbing in north central Florida. J. Plant Pathol. 95:361-371.

Shimwela, M. M., Schubert, T. S., Albritton, M., Halbert, S. E., Jones, D. J., Sun, X., et al. 2018. Regional Spatial-Temporal Spread of Citrus Huanglongbing Is Affected by Rain in Florida. Phytopathology®. 108:1420-1428 Available at: https://apsjournals.apsnet.org/doi/10.1094/PHYTO-03-180088-R [Accessed October 2, 2020].

Simpson, D., Rue, H., Riebler, A., Martins, T. G., and Sørbye, S. H. 2017. Penalising Model Component Complexity: A Principled, Practical Approach to Constructing Priors. Stat. Sci. 32:1-28.

Sparks, A. H. 2018. nasapower: A NASA POWER Global

Meteorology, Surface Solar Energy and Climatology Data Client for R. J. Open Source Softw. 3:1035.

Teck, S. L. C., Fatimah, A., Beattie, A., Heng, R. K. J., and King, W. S. 2011. Seasonal Population Dynamics of the Asian Citrus Psyllid, Diaphorina citri Kuwayama in Sarawak. Am. J. Agric. Biol. Sci. 6:527-535 Available at:

https://thescipub.com/abstract/ajabssp.2011.527.535 [Accessed May 4, 2021].

Tomaseto, A. F., Miranda, M. P., Moral, R. A., Lara, I. A. R. de, Fereres, A., and Lopes, J. R. S. 2018. Environmental conditions for Diaphorina citri Kuwayama (Hemiptera: Liviidae) take-off. J. Appl. Entomol. 142:104-113 Available at: https://onlinelibrary.wiley.com/doi/abs/10.1111/jen.12418 [Accessed April 12, 2021].

Tsai, J. H., Wang, J.-J., and Liu, Y.-H. 2002. Seasonal Abundance of the Asian Citrus Psyllid, Diaphorina citri (Homoptera: Psyllidae) in Southern Florida. Fla. Entomol. :446-446 Available at: https://journals.flvc.org/flaent/article/view/75122 [Accessed May 8, 2021].

Van Vuuren, S. P. and Da Graça, J. V. 1993. Variable transmission of African greening to sweet orange. Pages 264-268 in Proc. 12th Conference of the International Organization of Citrus Virologists. University of California, Riverside. Available at: https://swfrec.ifas.ufl.edu/hlb/database/pdf/00000503.pdf

Watanabe, S. 2010. Asymptotic Equivalence of Bayes Cross Validation and Widely Applicable Information Criterion in Singular Learning Theory. J. Mach. Learn. Res. 11:3571-3594.

Wickham, H., Averick, M., Bryan, J., Chang, W., McGowan, L. D., François, R., et al. 2019. Welcome to the tidyverse. J. Open Source Softw. 4:1686.

Wulff, N. A., Daniel, B., Sassi, R. S., Moreira, A. S., Bassanezi, R. B., Sala, I., et al. 2020. Incidence of Diaphorina citri Carrying Candidatus Liberibacter asiaticus in Brazil's Citrus Belt. Insects. 11:672 Available at: https://www.mdpi.com/20754450/11/10/672 [Accessed May 8, 2021].

Xie, Y., Allaire, J. J., and Grolemund, G. 2018. R Markdown: The Definitive Guide. Boca Raton, Florida: Chapman and Hall/CRC. Available at: https://bookdown.org/yihui/rmarkdown. 